\title{
Solidariedade intelectual Sul-Americana: ecos dos ensinamentos do Mestre Rodó no Paraguai
}

\author{
South American Intellectual Solidarity: \\ Echoes of Master Rodó's teachings in Paraguay
}

Elisângela da Silva Santos*

Resumo: Este artigo discute a difusão dos ensinamentos do pensador uruguaio José Enrique Rodó (1871-1917) no Paraguai do começo do século XX, contexto marcante para a geração de intelectuais do país nascida na primeira década após a guerra da Tríplice Aliança (18641870), a qual buscou construir uma narrativa de revalorização nacional. A partir da análise de resenhas de obras de Rodó publicadas no Paraguai, de homenagens prestadas a ele pela juventude universitária paraguaia e do intercâmbio de correspondências com autores paraguaios, estabelece-se como hipótese que os ecos de seus ensinamentos e de suas lições tiveram ressonância naquele país e promoveram um diálogo intelectual transnacional, a partir da ideia de Pátria Continental, que Rodó projetou para o continente nesse momento.

Palavras-chave: José Enrique Rodó; Paraguai; Comunidade Intelectual Transnacional; Juventude.
Abstract: This article discusses the dissemination of the teachings of the Uruguayan thinker José Enrique Rodó (1871-1917) in Paraguay at the beginning of the twentieth century, a remarkable context for the generation of Paraguayan intellectuals born in the first decade after the War of the Triple Alliance (1864-1870), which sought to construct a narrative of national revaluation. Based on the analysis of the reviews of Rodó's works published in Paraguay, as well as the tributes offered to him by young Paraguayan academics and the exchange of correspondence with Paraguayan authors, we suppose that it is possible that the echoes of his teachings and lessons resonated in that country and promoted a transnational intellectual dialogue, based on the idea of the Continental Homeland, which Rodó projected to the continent at that time.

Keywords: José Enrique Rodó; Paraguay; Transnational Intellectual Community; Youth.

\footnotetext{
* Universidade Federal de Jataí (UFJ), Jataí, GO, Brasil. licass20@gmail.com <https://orcid.org/00000003-2401-9999>
} 


\begin{abstract}
“(...) el hecho fundamental de que somos esencialmente 'unos'; de que lo somos a pesar de las diferencias, más abultadas que profundas, en que es fácil reparar de cerca, y de que lo seremos aún más en el futuro, hasta que nuestra unidad espiritual rebose sobre las fronteras nacionales y prevalezca en realidad política."
\end{abstract}

(Rodó, 1957, p. 1225).

O debate em torno do projeto civilizatório a ser construído no continente latino-americano foi tema nuclear para a compreensão dos movimentos intelectual e cultural empreendidos por José Enrique Rodó no final do século XIX e início do XX, no que diz respeito aos países hispano-americanos. As reflexões que desaguam na sua obra mais conhecida, Ariel (1900), vinham sendo desenvolvidas por ele desde a última década do século XIX. Ao publicar esta obra, o autor pretendia dar uma resposta às circunstâncias históricas. Trata-se de um ensaio de interpretação que inseriu as preocupações e os reajustes ideológicos daquele momento.

Naquele período, o contraste entre o "desenvolvimento" da América Saxã e o "atraso" da América Latina era a principal questão para os pensadores latino-americanos. A obra se localiza num período-chave para a história do continente, pois a Espanha perdia suas últimas colônias em 1898 e os Estados Unidos se erigiam como a grande potência continental. Porém, o texto alerta sobre os perigos que esta concepção e estes valores poderiam acarretar para a América Latina: utilitarismo, intolerância, especialização, tecnocracia, vulgaridade e mau gosto.

No livro, o professor Próspero convoca seus alunos à sua última lição magistral, cujas pautas éticas e estéticas são pronunciadas àqueles que enfrentarão uma vida ameaçada pelo imperialismo ianque, pelos materialismo e utilitarismo mesquinhos de uma sociedade que começava a se modernizar no sentido norte-americano.

Real de Azúa (1976, p. VII) apontou que o tom do chamado era de urgência. Havia uma pedagogia social, as soluções e as forças mobilizadoras aludiam sempre ao coletivo, ao americano. Deste projeto, ou desta missão intelectual, surge uma versão do arielismo, encarado como um espaço de sociabilidade juvenil que buscava latinizar a América, tornar o continente familiar aos habitantes, unir as fronteiras nacionais e recuperar o elo perdido com a 
Independência política. É válido pontuar que o chamado para a união do continente moldava um corpo de textos de Rodó, não somente Ariel, e não possuía uma dimensão institucional, e sim partia de um esforço coletivo de reunir novamente os países do continente, de forma fraternal e espiritual. Alfonso García Morales (1992) sustentou que o discurso arielista se dedicava a traçar um programa de orientação moral e a fixar nos jovens ideais para enfrentar a vida e fazer realizar suas esperanças.

Deste modo, o discurso arielista é um programa para a geração vindoura e, como disse Rodríguez Monegal (1957), traz como um dos seus temas principais uma concepção plena e integral do homem. Para que este objetivo fosse atingido, havia a necessidade da eficácia moral da educação estética.

Seu chamado se dirigia a uma elite intelectual jovem e heroica, capaz de defender a latinidade em oposição ao espírito norte-americano. No pensamento de Rodó, como sustenta Belén Castro Morales (1999), a redefinição da crítica, do intelectual, do ensino e da cultura americana constituem os cimentos de um projeto para o futuro, de uma filosofia cultural definida no marco do arielismo e inspirada pelo princípio proteico de uma evolução constante no individual e no social, com todos os traços de uma teleologia cultural.

Além da resistência à política expansionista norte-americana, há um forte apelo à religação continental e um chamado aos jovens para a construção solidária de uma "pátria intelectual”: "[...] yo creo que América necesita grandemente de su juventude"2 (Rodó, 1957, p. 208). Observa-se a necessidade de um programa para a geração de jovens atentos às questões do continente, principalmente no que dizia respeito à educação estética e humanista, dando-se espaço para uma educação especializada e técnica. A contribuição rodoniana pode ser lida como um discurso pedagógico que moveu grande parte da retórica geracional do início do século XX e abriu vasos comunicadores com uma sociedade que procurou, na cultura, as suas bases identitárias, os seus conteúdos integracionistas e novos fundamentos de valor.

O chamado americanismo constituiu-se a parte "medular" da produção de Rodó. Faz parte do conjunto de ideias éticas, estéticas, políticas e sociais de sua obra e se divide em quatro elementos principais: literário, cultural, político e heroico (Ardao, 1970). Esse conceito se desdobra na questão da originalidade do continente Latino-Americano, que deveria sempre retomar a ligação com a civilização espanhola. O descobrimento da nossa vocação cultural se realizaria por meio da exploração da região oculta e inesgotável que representava a América Latina. Somente desta forma poderíamos nos desenvolver e mostrar ao mundo a nossa verdadeira personalidade. $\mathrm{O}$ alcance desse 
objetivo só seria possível através da ação intelectual séria e herdada da alta cultura, e também a partir da "unificação intelectual" dos nossos povos.

Como analisou Eduardo Devés-Valdés (2012), Rodó e seu arielismo contribuíram para a consolidação de redes intelectuais que desenvolveram uma "consciência comum". O estudo dessas redes é um método capaz de detectar os contatos de longa duração entre pessoas dedicadas à tarefa intelectual, buscando-se a existência de canais de circulação de ideias e de nós, de enlaces mais ou menos densos, nos quais se gestam diversas iniciativas.

É esta dimensão das redes intelectuais que estamos tratando como solidariedade intelectual, marca frequente na produção rodoniana desde sua juventude. Como exemplo disso, podemos mencionar o papel da Revista Nacional de Literatura y Ciencias Sociales, dirigida por Rodó, pelo amigo Victor Perez Petit e pelos irmãos Daniel Vigil e Carlos Vigil entre 1895 e 1897, que teve sua sede em Montevidéu, cujo objetivo era expressar "a vida cerebral" das novas gerações. A Revista estabeleceu contato com diversas capitais da América Hispânica e reuniu uma rede de intelectuais interessados na construção de projetos literários e sociais para o continente. A ideia de unidade intelectual americana era uma das inspirações que estimularam os diretores da Revista, vista como um veículo adequado para conquistar a confraternidade literária e cultural do continente. De acordo com José Enrique Etcheverry:

Para el autor de Ariel siempre fue una idea entrañable la publicación de una revista americana que significaba el ágora intelectual de las nuevas generaciones y el instrumento más adecuado para lograr la confraternidad del Continente. (Etcheverry, 1950a, p. 269)3.

Pode-se dizer que Rodó sempre esteve atento ao estabelecimento de uma estratégia transnacional, a fim de fortalecer laços entre uma intelectualidade situada em diferentes pontos do continente, visando a integração e o fortalecimento de saberes. Neste sentido, ele adotou a articulação entre a intelectualidade hispano-americana e a espanhola em diversos formatos: por meio de revistas, cartas, artigos, manifestos, prólogos, aforismos, novelas filosóficas, entre outros; reafirmando a história compartilhada entre as nações do continente. Em sua política pedagógica literária, o traço marcante da solidariedade que unia todas as nações supria os conflitos, as disputas e as lutas anteriores. Em suas palavras:

Parecerá punible a los que defienden como el sagrado símbolo de la nacionalidad intelectual, el aislamiento receloso y estrecho, la fiereza de la independencia lite- 
raria que sólo da de sí una originalidad obtenida al precio de la incomunicación y la ignorancia candorosa. (Rodó, 1957, p. 152) .

Como afirmou Belén Castro Morales (2004), é na articulação entre o estético, o retórico e o político que se desenvolveu a nova concepção do intelectual como personagem público.

Rodó estabeleceu contato com diversos pensadores hispano-americanos e espanhóis. Seu vasto epistolário revela o intercâmbio com autores que, naquele momento, também estavam preocupados em romper com o isolamento da cultura nacional, valendo-se de estratégias como o jornalismo, a revista e as cartas. Conforme Devés-Valdés (2007), essa rede considera Ariel como um manifesto.

A classificação da obra Ariel como um manifesto, mesmo para a geração paraguaia de intelectuais que viveram as implicações nefastas da Guerra contra o seu país, poderia ser considerada uma atitude incoerente, já que o texto é escrito por um autor uruguaio também partícipe ativo da empreitada que teve consequências dramáticas ao Paraguai, assim como ao Brasil e à Argentina. Segundo nossa hipótese, a figura de José Enrique Rodó surgiu com força justamente num período em que os intelectuais da "Geração dos 900" tentavam superar o desconhecimento da existência do Paraguai enquanto país, bem como a sua fama de país iletrado, indígena e devastado. Como apontou Marakan: "De esta manera, el esfuerzo paraguayo por la integración cultural con el continente inicia por la negación persecutoria del propio, formado a lo largo de su historia marcada pelo aislamiento" (Marakan, 2016, p. 19)

Esta situação ratifica, na nossa visão, a importância de se discutir o arielismo rodoniano sob o prisma de seus deslocamentos e de sua atualidade, uma vez que Rodó almejou a consolidação de um projeto civilizatório para a América Latina. Este ambicioso objetivo apontava para ações diplomáticas amistosas, recuperando os laços de solidariedade entre os países, agora sim, através de uma política internacional de equidade, de concordância e de solidariedade americana. Como veremos por meio do contato epistolar com Juan O’Leary, Rodó não deixa de reconhecer as trágicas consequências da guerra para os países envolvidos. A percepção da sua "pátria intelectual" não desprezava a responsabilidade histórica, mas sua estratégia trazia como princípio a esperança na "raça latina". Para isso, o diálogo cultural entre os países, no alvorecer do século XX propunha a regeneração dos valores espirituais e idealistas, por meio de uma política pedagógica orientada a partir da cultura.

Além das relações estabelecidas através das cartas, alguns autores já res- 
saltaram ecos dos ensinamentos rodonianos no Peru. Mencionamos o trabalho de Emir Rodríguez Monegal (1953), que analisa as relações intelectuais entre Rodó e Francisco García Calderón. Já René de Costa (1970) ressalta em seu trabalho a presença de Rodó na literatura chilena; enquanto Raffaele Cesana (2016) analisa tal presença no México; Belén Castro Morales e Gustavo San Román (2009) apontam a recepção da obra do autor em Cuba; e José Enrique Etcheverry (1950a) aponta a recepção rodonina no Brasil.

Este texto observa os esforços de autores paraguaios em construir conexões com essa ampla pátria hispano-americana, através da adesão aos ensinamentos do mestre José Enrique Rodó, direcionados à juventude do continente, o que possibilitou a circulação de debates, agendas e, ao mesmo tempo, a configuração de um projeto educativo humanista capaz de integrar as letras uruguaias e paraguaias. O objetivo desta análise é expor a recepção dos ensinamentos rondonianos por parte da intelectualidade paraguaia do início do século XX.

O estudo da recepção de Rodó no Paraguai se deu a partir das seguintes fontes: 1) de resenhas de seu livro Ariel, escritas por Ignacio Pane, em 1901, na Revista del Instituto Paraguayo, e por Eloy Fariña Nuñes, em 1917; 2) de homenagens rendidas a Rodó pela juventude universitária na ocasião de sua morte; 3) de escassas correspondências trocadas pelo autor com os intelectuais Rafael Barrett, em 1910, e Juan de O’Leary, em 1915. Estes registros, datados da primeira metade do século XX, produzidos num contexto em que tanto a institucionalização editorial quanto a universitária eram frágeis no continente, denotam o resultado de uma análise histórica, cultural e intelectual da região, que buscava a unidade. E a relação com esses autores do Paraguai revelam que, mesmo muitas vezes sendo considerado um país isolado, a sua intelectualidade se esforçou para que o arielismo e o americanismo integrassem também esse núcleo cultural.

Eduardo Devés-Valdés (2006, p. 301), ao analisar o pensamento paraguaio do século XX, comenta que o país é um dos mais ausentes no cenário intelectual latino-americano - mais ausente, inclusive, do que países que tiveram problemas parecidos, como extensas ditaduras e economias "hipersubdesenvolvidas”. Além disso, ressalta que a avaliação do pensamento paraguaio tem pouca difusão dentro e fora de seus limites fronteiriços, apesar de seus importantes parentescos com linhas latino-americanas. No entanto, neste país, considerado muitas vezes pelas ciências sociais latino-americanas como isolado, periférico e hermético, vemos os esforços de intelectuais coincidindo com o ambicioso projeto de José Enrique Rodó de construção da "pátria continental”. 


\title{
O INTELECTUAL COMO ORIENTADOR DE HOMENS E DE MULTIDÕES
}

\begin{abstract}
"A su veneranda sombra pide hoy el corazón de los orientales bendiciones para la tierra paraguaya; bendiciones que fructifiquen en paz y ventura para su pueblo; en adelanto triunfal para su civilización, tan esforzadamente mantenida en promesas por su generosa juventud."
\end{abstract}

(Rodó, 1919, p. 45)

Nos textos escritos entre o final do século XIX e o início do XX, Rodó incorporou a perspectiva do intelectual como orientador de homens e multidões, exercendo o magistério (Real de Azúa, 1976, p. XLVI). No mesmo sentido, Belén Castro Morales (2016) aponta que Rodó assumiu, desde sua juventude, a escritura como espaço de reflexão, como forma de "propaganda" e como uma heroica e pacífica milícia educativa à margem das instituições. Desde o início de seu trabalho, criou redes comunicativas cujo objetivo era estender seu projeto de "união fraternal" entre os intelectuais, a partir do âmbito transnacional. Para isso, recorreu à ideia de Magna Pátria, cuja base identitária comum ibero-americana nutria a confraternidade das almas.

Leopoldo Zea (2002) apontou que a mensagem à juventude de seu tempo estava motivada pelas mudanças históricas que se iniciam em 1898, com a ruína do velho império espanhol. Tal derrota legou, como visão de mundo, a necessária construção da obra da inteligência desta região, que se encontrava em aberto, sendo Rodó um dos pioneiros em apontar a necessidade de os países do continente saírem de seu quadro exclusivamente nacional e formularem uma grande nação mediterrânea latina.

O final do século XIX e o início do XX também foi um período marcante para a intelectualidade paraguaia, que além de refletir sobre as tremendas consequências sociais e econômicas resultantes da Guerra do Paraguai, também produziu uma narrativa de revalorização da língua, da cultura e do povo. Esta tentativa de construção de um campo intelectual foi conduzida pela chamada "Geração dos 900".

Entre os expoentes desta geração estavam Blas Garay (1873-1899), Juan O’Leary (1879-1969), Manuel Domínguez (1868-1935), Fulgencio Moreno (1872-1933), Arsenio Lopes Decoud (1867-1945), Ignacio Pane (1880-1920), Eligio Ayala (1879-1930), Manuel Gondra (1871-1927), Hérib Campos Cervera 
(1879-1922), Teodosio Gonzáles (1871-1932) e Gualberto Cardús Huerta (1878-1949).

Em 1895, este mesmo grupo fundou o Instituto Paraguayo, que, segundo Bareiro Saguier (1964), foi o primeiro centro de cultura superior, tendo como meio principal de expressão uma revista com o mesmo nome, cujos artigos resultavam de debates travados acerca dos problemas nacionais - foram publicados, ao todo, 64 números do periódico entre os anos de 1897 a 1909. Tratam-se de escritores políticos, dedicados a uma "literatura aplicada", que consolidaram o primeiro período de uma geração nas letras no país. A circunstância cultural e social do Colegio Nacional e do Instituto Paraguayo foi a Guerra da Tríplice Aliança, o que motivou um "quehacer" geracional, ou seja, a afirmação da nacionalidade, a recriação da consciência coletiva diante do perigo recente de desintegração representado pela Guerra. Esse grupo fomentou o ensino de música e idiomas, o desenvolvimento de uma literatura, além de estimular as práticas de exercícios físicos por meio da ginástica e da esgrima.

Conforme Raúl Amaral (2006), o novencentismo, ou o arielismo, no Paraguai, pode ser comparado com a geração espanhola de 1898 e com a geração dos novecentos uruguaia. Esse movimento se deve, em grande medida, ao auge do modernismo literário (1898-1928), estendendo-se aos estudos sociológicos desde 1906 até 1924, às investigações etnográficas acentuadas em 1899, à aplicação de novos métodos de ensino (1903-1927) e aos primeiros indícios de superação do positivismo.

Liliana Brezzo (2010) aponta que o pós-guerra representou um momento carregado de responsabilidades nacionalistas, cujo objetivo maior seria a reconstrução do país, sob um crescente influxo do nacionalismo. Esta "reparação histórica" foi o condicionante que converteu alguns produtos históricos em "verdades" repletas de epopeia e de patriotismo: "[...] afirmar los valores espirituales de la nación renaciente de la catástrofe" (Brezzo, 2010, p. 234) ${ }^{7}$. A questão política intervinha de maneira muito intensa nesses escritores. Rodriguez Alcalá (1970) demonstra que as exigências do ambiente não favoreceram a formação de "intelectuais de gabinete", pois esta geração não podia se dedicar exclusivamente à atividade do cultivo das ciências e das letras. Portanto, como podemos observar, a relação entre intelectuais, escritores, críticos e políticos no Paraguai ocorria, no final do século XIX e no início do XX, de modo muito estreito, representando uma narrativa adequada ao momento político do país, que buscava uma unidade nacional.

Pode-se questionar a existência de uma relação intensa entre Rodó e autores paraguaios, no entanto, um olhar mais atento às produções de autores 
deste período demonstra que houve um esforço de ambos os lados para que o país também forjasse um sistema de relação entre a palavra e a cidadania. Júlio Ramos (2008) sublinha que a literatura ou as letras em geral haviam ocupado um lugar central na organização das novas sociedades latino-americanas. A literatura, modelo do ideal de uma língua nacional, racionalmente homogênea, teria sido o lugar (fictício, talvez) no qual se projetavam os modelos de comportamento, as formas necessárias para a invenção da cidadania, os limites e as fronteiras simbólicas, enfim, dos Estados em vias de consolidação.

Roa Bastos, em seu ensaio publicado em 1977, denominado "Paraguay. Isla rodeada de tierra", chamava a atenção para o fato de que os indagadores da cultura da nossa América não se esforçavam em desentranhar as causas que fazem da cultura paraguaia uma terra incógnita. O mesmo autor, ao referir-se ao "atraso" e à "marginalidade" da literatura paraguaia diante das literaturas latino-americanas, recuperava uma imagem recorrente.

Gaya Marakan (2016) aponta que a existência de rincões latino-americanos como o Paraguai - que historicamente se constituíram às costas das dinâmicas próprias do continente e que constituem ainda incógnitas para o restante da comunidade internacional - segue sendo um objetivo do ideal martiniano de integração de nuestra américa.

$\mathrm{O}$ discurso nacionalista divulgado pelos intelectuais paraguaios da "Geração dos 900" pretendia demonstrar o orgulho nacional, bem como um pretenso desejo de unificação cultural e socioeconômica dos vastos e diversos territórios da América pré-colombiana. A partir da segunda metade do século XIX, se observa um processo de abertura ao moderno, com a ocidentalização e a castelhanização forçada da população paraguaia, que passou a ver a cultura guarani como um atraso a ser superado.

Como observaremos, a geração do início do século XX foi leitora de Rodó e, como demarcou Claudio Maíz (2009), as histórias literárias hispano-americanas, desde o século XIX, estiveram compostas, de maneira exclusiva, a partir da centralidade do Estado-Nação. Tal particularidade produziu alguns isolamentos e distorções: por um lado, o estudo das vozes literárias nacionais separadas do contexto da América Hispânica; por outro, a consideração da literatura como expressão da nacionalidade, exacerbando o traço anterior.

Desta maneira, ao propormos repensar as relações entre contextos intelectuais periféricos, no caso do Paraguai e do Uruguai, estamos deslocando da Europa e dos Estados Unidos os vetores da difusão do conhecimento e da produção intelectual, que continuam centrados naqueles eixos, e analisando os processos de institucionalização da intelectualidade sul-americana de forma 
dinâmica, sem eliminarmos a perspectiva regional. Como apontou Eduardo Devés-Valdés (2007):

A la hora de pensar horizontalmente Sur-Sur, las redes intelectuales permiten descubrir circulaciones con mayor eficacia que la noción de "influencia", cargada tantas veces con la verticalidad Norte-Sur. (Valdés, 2007, p. 33) ${ }^{8}$.

É esse ponto de contato entre essa geração e José Enrique Rodó que, no final do século XIX, em 1896, forja a ideia de "pátria intelectual". Observa-se a necessidade de integração dos intelectuais dos diversos países que formam a Hispano-América, que tinha como um de seus objetivos enfrentar e saltar a barreira do confinamento nacional. A religação proposta por Rodó ocorre de forma intracontinental (e extracontinental, quando aponta a ligação indissolúvel existente entre a Hispano-América e a Espanha), conferindo uma nova dimensão ao pensamento e à literatura, que, para se fortalecerem e obterem originalidade, deveriam se abrir para o coletivo, transcendendo as fronteiras geográficas. Temos, portanto, a perspectiva de uma "comunidade imaginada transnacional". Belén Castro Morales (2016) aponta que esse seria o novo americanismo, que visava estabelecer uma função comunicativa de primordial importância para impulsionar um intercâmbio de escala continental e transatlântica entre os escritores que formavam sua pátria intelectual.

Maíz (2009) ressalta que a chamada metodologia das "redes intelectuais" contribui para revelar, no estudo dos fenômenos intelectuais, algumas dimensões diversas, a partir de outras perspectivas. Portanto, é preciso fixar-se num horizonte metodológico que transcenda a centralidade do Estado-Nação e os respectivos paradigmas que o sustentam. Admite-se de antemão que as três dimensões - nação, geração e lugar - estejam em crise, já que estes princípios nos impedem de compreender, de maneira mais transversal, a produção cultural ibero-americana em sua relação com a Europa.

A análise da inserção transnacional de José Enrique Rodó nos serve como subsídio para melhor situarmos historicamente sua obra, gestada em um momento em que a intelectualidade hispano-americana buscava um estreitamento das relações e uma espécie de cooperação internacional, capaz de circular e constituir conexões por meio de revistas, correspondências, textos jornalísticos, etc.

Como apontou Maíz (2009), o termo pátria intelectual não se refere a uma relação direta com o poder. Esta comunidade imaginada não representa, de 
forma cabal, os laços vinculantes entre Estado e intelectuais. O âmbito em que se desenvolve esta comunidade é o artístico.

\title{
Rede intelectual Sul-Americana: o legado DE José E. Rodó À JUVENTUde INTELECTUAL PARAgUAIA
}

\begin{abstract}
"Paraguayos y orientales forman, sin duda, el más cabal ejemplo americano de aquella 'grande amistad' que Michelet soñaba ver consagrada en las relaciones de los pueblos. Reciprocidad de afectos y comunidad de intereses los vinculan. El Uruguay es el Paraguay Atlántico, el Paraguay es el Uruguay de los trópicos."
\end{abstract}

(Rodó, 1919, pp. 44-45)

A primeira manifestação sobre o impacto de Rodó, particularmente de Ariel, no Paraguai, foi uma resenha publicada por Ignacio Pane em agosto de 1901, na Revista del Instituto Paraguayo. O Instituto se constituiu num genuíno epicentro da cultura nacional. Seu salão de conferências, o cenário principal de suas atividades, recebia ilustres eruditos do país e estrangeiros convidados.

Pane integra a geração de autores paraguaios que iniciou, a partir de 1870 (ao fim da Guerra da Tríplice Aliança), um processo de recuperação da memória nacional. Para Brezzo (2004), houve um grande esforço desta geração em empreender uma comemoração em torno do centenário de independência da nação, que deve ser analisado no contexto das consequências que a Guerra teve em todos os campos da realidade, incluindo o cultural.

Pane, em sua resenha de Ariel, argumenta que a obra recebeu críticas americanas e espanholas positivas, porém, em seu país, ainda havia sido pouco lida: "Y sin embargo aquí en Asunción juraría que no son más de cuatro los que oyeron siquiera este nombre Ariel, sencillamente porque no ha llegado mayor número de ejemplares del libro"10 (Pane, 1901, p. 197).

Esta resenha foi publicada em agosto de 1901 - provavelmente chegaram mais números de exemplares do livro, posteriormente. Pane aponta no texto que o assunto na América é o seu porvir, pois um espaço repleto de jovens representa um lugar de ação, a "Atenas do Prata”. Os americanos, no intuito 
de se unirem diretamente, deveriam olhar para o passado e para o futuro. Além disso, o autor ressalta a importância da educação, que deveria ser completa para não mutilar a personalidade humana. Ademais, considera que o sentimento estético deveria ser a pedra angular da educação:

Ya que todos trabajamos en el taller, ni todos en la oficina, ni todos en el mostrador, que vayamos todos siquiera al Ateneo. Yo estoy con él. Creo con él que la especialización del progreso produce la estrechez del horizonte individual, su es que no se le aplica el correctivo del arte o de la religión. Pero no voy más allá, no voy hasta pensar con Próspero que esta estrechez individual mata el sentimiento de la solidaridad. Por el contrario, me parece que la crea; pues a medida que cada uno puede bastarse menos a si mismo más necesita de los demás. Y es en la necesidad, en el interés donde está la base de la solidaridad. Solo la caridad, entre lazos individuos-sociales, se funda en el afecto puro (Pane, 1901, p. 203) ${ }^{11}$.

Pane, ao apontar a necessidade dos sentimentos de solidariedade, de caridade e de afeto como possibilidades de construção de uma coletividade continental, parece solicitar que também o Paraguai ingresse neste desafio intelectual que a obra Ariel tem mostrado indispensável.

En el Paraguay, entre tanto, a menos de ser exagerado no puedo negar lo primero a hacerse es empezar. Que se debe subir no bajar; esto es, entrar en la planta baja, y después pasar al mirador; pero asegurando por supuesto de antemano un ascensor o una escala: teniendo como catecismo un libro como Ariel (Pane, 1901, p. 210$)^{12}$.

Ariel, portanto, surge como uma possibilidade de reconhecer que os intelectuais paraguaios se esforçavam para participar da unificação cultural que Rodó tanto propagava; surge, enfim, como um "catecismo". É neste sentido que Yamandú Acosta (2018) enxerga a obra, como um "eventual evangelho de uma teologia profana americanista” (Acosta, 2018, p. 34) que não transcende apenas no século, mas também em todo o espaço latino-americano, como expressão da cultura iniciada no século XX, tensionada entre identidade e modernidade. O papel do intelectual como condutor na busca de uma identidade nacional é um importante legado do arielismo, e essa geração paraguaia, agrupada em torno dos projetos de refundação da nação, reforça a importância continental de Rodó.

Também Pane aponta para a necessidade de se enxergar o país como uma potencialidade cultural em meio à consciência dos efeitos da crise causada 
pela Guerra do Paraguai. O autor considera que a "Geração dos 900" poderia se sentir parte do movimento arielista e integrar este projeto identitário continental. Neste sentido, podemos pensar na atuação de Rodó como um propagador de uma renovação no modo de se conceber o impulso intelectual em nosso continente. Segundo Liliana Weinberg (2018), Rodó desenha um modelo estético de comportamento social.

A literatura significava um órgão da vida civilizada. Este ideal arielista, que se expandia na América Hispânica, também influenciou os autores paraguaios. Como ressaltou Gaya Marakan (2013), o começo de século foi marcado, no Paraguai, por teorias estrangeiras que atribuíam aos paraguaios uma pressuposta selvageria e, portanto, a incapacidade para a vida democrática e moderna. Disso emerge o discurso da grandeza e da particularidade do povo paraguaio: em sua natureza, raízes, componentes e predisposições. Assim, criam-se mitos nacionais e se elegem heróis oficiais.

Pane aponta em sua resenha que o século XIX, farto de matemática e de positivismo - o século do vapor e dos caminhos de ferro -, não prioriza a imaginação. No entanto, constata que Ariel, ao surgir, cumpre a função da necessidade de um sentimento de educação estética. Lamenta, entretanto, ao constatar que a população sul-americana estaria à mercê de educadores "nordomanos": evolucionistas, positivistas, enganados pela crença de que a sociedade e o homem têm como finalidade principal o comércio e a indústria. Deste modo, Pane também segue na esteira rodoniana, realizando a crítica aos preceitos norte-americanos que ultrapassavam as fronteiras daquele país. Adverte que, se Rodó tivesse imitadores, entusiastas jovens como ele, os povos sul-americanos poderiam ter esperança.

Desta maneira, o americanismo literário praticado pelos autores da chamada "Geração dos 900", tanto paraguaia quanto uruguaia, não era um programa restrito à arte e à literatura. Como sublinhou Mariano Morinigo (1967), tratava-se, sobretudo, da afirmação da vida e de um estilo próprios, e da reiterada autonomia através do literário, além de uma oportunidade de se exibir esta intelectualidade que vicejava em zonas marginais da cultura ocidental, chamando a atenção do público sobre ela.

Outra ocasião de ressonância da presença de Rodó no Paraguai se deu em 1913, quando os jovens do Centro Estudantil de Direito receberam a Delegação Uruguaia naquelas plagas, em função das comemorações da independência do país, ocorrida em 1811. Esta delegação portava uma mensagem de Rodó à juventude paraguaia e apontava a necessidade de uma inquebrantável unidade da Magna Pátria hispano-americana: 
Porque si la comunidad de origen, del idioma, de la tradición, de las costumbres, de las instituciones, de lo interés, de los destinos históricos; y de la contigüidad geográfica, y cuanto puede dar fundamento real a la idea de una patria, no bastan para que el lenguaje del corazón borre, entre nuestros pueblos, las convencionales fronteras y dé nombre de "patria" (Rodó, 1919, p. 43) ${ }^{13}$.

Esta mensagem foi republicada no livro de $1919^{14}$, lançado pela Biblioteca dos estudantes de Direito, que se intitulava Rodó: homenaje de la juventud paraguaya, o qual apresenta, após seu título, a seguinte descrição: "Fue un pensador y poeta da vez: en él se fundieron mediante el milagro de una alquimia misteriosa, Sócrates y Platón”. Esta homenagem é sintoma de que Rodó foi um autor lido e respeitado pela juventude universitária do país.

Esta obra se insere na coleção Biblioteca Paraguaya del Centro de Estudiantes de Derecho, da Universidad Nacional de Asunción, a primeira iniciativa editorial do Paraguai, a qual procurou lançar uma coleção de títulos cujo objetivo era o de refletir sobre o país, muito influenciados pelo nacionalismo que emergiu nesta geração de intelectuais interessada no movimento de reconstrução do país.

Caballero Campos (2012) assinala que os membros do Centro Estudantil propiciaram atividades culturais ou comemorativas da independência paraguaia em 1911. Juan Stefanich (1889-1976) foi o presidente do Centro e também o diretor da Biblioteca até 1925, quando a mesma encerra suas atividades. É ele quem assina os prólogos das obras de Juan E. O’Leary e de Eloy Fariña Núñez, que analisaremos a seguir. Constavam entre os objetivos da Biblioteca: a) a difusão do bom nome do Paraguai, através de sua ciência e de sua cultura; b) o desempenho de atos eficazes de um americanismo prático, permitindo-se, através dos livros, a construção dos vínculos entre as juventudes estudiosas da América; c) o estímulo à produção científica no país e; d) a produção do esclarecimento e do conhecimento da História do Paraguai (Stefanich, 1925, p. I).

Rodó desfrutou de muito prestígio entre esses estudantes, tendo sido o único autor não paraguaio a ter um livro publicado por esta biblioteca, intitulado Rodó. Colección de artículos y discursos, de 1918. Na abertura desta obra, produzida na ocasião de sua morte, aponta-se que o país sofreu profunda dor, e que o chamado "funeral civil" celebrado demonstrava quão grande era a admiração que lhe era rendida, evidenciando-se os ótimos frutos colhidos da semente plantada na alma da juventude pela elevada prédica de Próspero. Por fim, os jovens oferecem a obra à memória do mestre, cuja simbologia estaria para sempre na alma da juventude americana. 
Discursaram na ocasião o presidente do Centro de Estudantes de Direito, Juan Stefanich, os estudantes Luis Ruffinelli, Juan Vicente Ramirez, Pedro P. Sanamiego e o pensador Natalício González. Além disso, a obra também incorpora uma carta de 1915, destinada ao intelectual paraguaio Juan O'Leary. Em todos os discursos, o tom é o mesmo: referem-se a Rodó como o grande mestre latino-americano que fala à juventude do continente, uma "flor latina" que pede a integração dos povos formadores da grande pátria, um gênio que constrói uma obra imortal: tolerante, compreensivo e potente.

Juan Stefanich salientou em seu discurso que muitos do Centro deviam a confiança e a vida à virtude redentora dos "nobres ensinamentos" rodonianos, e ao encanto de suas "máximas salvadoras". Os paraguaios seriam filhos de uma "terra atormentada" por contratempos ou dificuldades. Entretanto, o país se faria grande e admirado, não pela virtude do ódio e nem pela virtude do sangue vertido nas guerras insensatas, mas sim pelo trabalho e pela perseverança dos bons, bem como pelo "nobre ardor" de sua juventude (Stefanich, 1919, p. 13).

Em sintonia, Luis Ruffinelli aponta que, a partir dos ensinamentos de Rodó, não estaria longe o dia em que os ideais dos povos do sul se integrassem ao "robusto tronco", forte e rigoroso; e a "flor latina" se mostraria "um grande, imenso e superior povo que encarnará a visão do Mestre" (Ruffinelli, 1919, p. 20). Já Natalicio González reforça as percepções de Ruffinelli e Stefanich, afirmando que Rodó foi o mais tolerante e compreensível dos pensadores americanos, um mestre, um potente pensador. E concluía que, com ele, a América guardava seu mais "precioso tesouro" e as suas "gloriosas dádivas" (González, 1919, p. 37).

Este livro simboliza a importância que as ideias e os ensinamentos de Rodó tiveram no Paraguai. Essa geração de jovens paraguaios, preocupada com a cultura, a história, a ciência, as artes e a literatura, mostrava também seu interesse nos projetos de religação continental que a obra de Rodó tanto propagou. Observa-se nesses depoimentos, assim como na resenha de Pane, um forte apelo à reparação nacional e uma busca à superação dos males causados pela Guerra.

Na mensagem a seguir, proferida por Rodó em 1913 e republicada na obra em sua homenagem, há o reconhecimento da "viril juventude" como a força social capaz de impulsionar o progresso:

Levante la noble, la viril juventud paraguaya, su generoso espíritu a la altura de esa necesidad de los tiempos; haga obra de paz con la palabra y con la acción; 
cifre su altivez heroica en vencer dentro de sí misma la tentación de las pasiones, y habrá ganado una gloria tan alta y tan pura que ninguna generación podrá aspirar a otra mayor (Rodó, 1919, p. 42) ${ }^{15}$.

Observa-se uma afirmação da virilidade da juventude, que, apoiada numa reação espiritual, num equilíbrio humanista, era impulsionada a uma altivez heroica e convidada a vencer as "tentações" e as "paixões" - talvez, uma alusão às tentações de substituir a razão pela força, o altruísmo pelo egoísmo, a qualidade pela quantidade, elementos questionados por Rodó e caracterizados por ele como norte-americanos. A civilização embrionária, incompleta e disforme que a América Latina representava necessitava forjar uma consciência latino-americana, principalmente entre os jovens letrados, mas ainda dispersos do continente.

Outro intelectual que apontou a recepção de Rodó no Paraguai foi o espanhol ali exilado Rafael Barrett (1876-1910) ${ }^{16}$, o qual teve livros publicados no Uruguai, na Venezuela, na Costa Rica, em El Salvador, no México, na Itália e na Suíça. Em seu artigo publicado no extinto jornal uruguaio La Razón, em junho de 1912, há uma resenha sobre o livro de Rodó Motivos de Proteo. Nela, Barrett diz temer o mesmo que Pane: que Rodó não seja conhecido no Paraguai, onde circulam muitas ideias europeias, enquanto se ignora o melhor da atual literatura sul-americana. $O$ autor aponta que não seriam apenas $o$ crítico e o psicólogo que falam nas páginas de Proteo, mas também o poeta e o moralista; um professor embebido de cultura clássica, um curioso dos modernos estilos e um filósofo anti-modernista contemporâneo, que não se limita no conhecimento da ciência em si mesma - ela seria, ao contrário, uma disciplina heroica de autoemancipação para todos nós. Rodó, segundo Barrett, prefere ser um apóstolo intelectual; sua linguagem estaria impregnada de uma simpatia profunda e de unção laica.

¡Qué necesitados están el Paraguay, y la América entera, de talentos como Rodó, de maestros como él, si es licito llamar maestro a los que rehúyen toda jefatura, a los campeones de la tolerancia que nos empujan por un solo camino, pero los iluminan todos; a los que no nos proponen una teoría única, ni un dogma, por

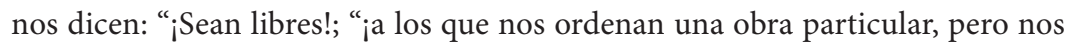
desatan las manos!” (Barrett, 1912, p. 26) ${ }^{17}$.

Barrett prossegue sua análise dizendo que, além de psicólogo, crítico e moralista, Rodó é múltiplo: amor à ordem, além de individual, disciplina e autocultura. O que caracteriza Motivos de Proteo é o ascetismo intelectual, o 
horror à ironia, o carinho à solidão e ao silêncio: "Rodó es de los verdaderos maestros, es decir, de los libertadores; y siguiendo sus ideas pensaremos que desde la aparición de su obra el alma del Uruguay se ha dignificado y ha crecido" (Barrettt, 1912, p. 33).

Também Rodó, num dos artigos enfeixados em 1913, no livro El mirador de Próspero, dedica uma análise ${ }^{18}$ a um livro de Barrett, intitulado Moralidades Actuales. Trata-se da única obra de Barrett publicada em vida, em Montevidéu, em 1910, composta por uma reunião de artigos escritos ao longo de três anos. Nesta crítica de Rodó, escrita no mesmo ano, o autor aponta que cronistas de fama europeia, escrevendo fora do bulevar, não teriam nada de interessante a dizer a ninguém, e que, mesmo escrevendo do bulevar, são incapazes de comunicar, numa página, o interesse efêmero de algo que contam ou comentam. No entanto, no caso de Barrett, constata que, mesmo escrevendo para o público de Montevidéu, o autor produz coisas interessantes, que fazem sentido em todas as partes do mundo.

Una de las impresiones en que yo podría concretar los ecos de simpatía que la lectura de sus crónicas despierta a cada paso en mi espíritu es la de que, en nuestro tiempo, aun aquellos que no somos socialistas, ni anarquistas, ni nada de eso, en la esfera de la acción ni en la doctrina, llevamos dentro del alma un fondo más o menos consciente, de protesta, de descontento, de inadaptación, contra tanta injusticia brutal, con tanta hipócrita mentira, contra tanta vulgaridad entronizada y odiosa, como tiene entretejidas en su urdimbre este orden social transmitido al siglo que comienza por el siglo del advenimiento burgués y de la democracia utilitaria (Rodó, 1957, p. 636) ${ }^{19}$.

A crítica literária também foi utilizada por Rodó como uma articulação intelectual latino-americana. A América Latina seria uma vasta nação indissolúvel, que possuía o mesmo passado, a mesma face cultural e também um destino comum, apesar das diferenças entre as vertentes seguidas. Deveria, portanto, estar unida para lutar contra a vulgaridade e a injustiça social advindas com a nova mentalidade e a nova organização social utilitária e progressista, que obstaculizavam a percepção e o reconhecimento mútuo da necessária religação continental.

Observa-se que essa solidariedade intelectual também inclui na pauta o debate de temas coetâneos. Nesta relação "virtual" com Barrett, ambos apontam a necessidade da alta cultura, da luta contra a injustiça social e da liberdade, em tempos de ameaças utilitaristas. Além disso, como aponta García Morales 
(1992), Rodó acreditava na tolerância como elemento muito importante de qualquer atividade ou processo intelectual, pois os homens mais sábios, os povos mais adiantados ou as épocas mais fecundas eram as mais tolerantes e, ademais, a tolerância capacitava o crítico a penetrar em uma obra de arte.

Os livros de autores paraguaios que demonstraram a influência de Rodó no Paraguai, os quais mencionaremos a seguir, se inserem na coleção Biblioteca Paraguaya del Centro de Estudiantes de Derecho da Universidad Nacional de Asunción.

Como apontamos, o outro autor paraguaio que também se correspondeu com Rodó foi Juan E. O’Leary (1879-1969). Conforme Liliana Brezzo (2019), desde os primeiros anos do século XX, O’Leary buscou fomentar contatos epistolares com intelectuais estrangeiros, dentre eles Rodó. Ele foi uma das figuras intelectuais mais relevantes da primeira metade do século XX no Paraguai. Em seu discurso histórico e interpretativo sobre a Guerra do Paraguai, o país vivia feliz e próspero, até o imperialismo brasileiro e o argentino condenarem sua nação a uma completa derrota.

O livro Nuestra Epopeya: guerra del Paraguay tem 651 páginas e consiste na compilação de textos divulgados por O'Leary em diferentes formatos. Artigos, folhetos, conferências, que, segundo os leitores, configuravam uma "literatura pátria" cujo propósito era levantar o espírito e fortalecer o patriotismo, enquanto o autor se preparava para poder oferecer ao público a sua obra definitiva e monumental sobre a tragédia americana que sofreu o Paraguai. A obra buscou abordar os antecedentes da Guerra, os cantos da epopeia, os heróis, as batalhas e, por fim, as consequências do conflito cinquenta anos depois.

Lo que siento - he de agregar para terminar - ante el éxito definitivo de mi propaganda, es, sobre todo, un inmenso optimismo, que me hace creer que esperan días mejores al Paraguay, días de reconciliación y paz, días de prosperidad, en los que seguramente volveremos a ser lo que fuimos, fuertes y respetados, algo más que una simple expresión geográfica, un factor decisivo en los destinos de América (O’Leary, 1919, p. 648) ${ }^{20}$.

Essa maneira de conceber o país se inseria no discurso nacionalista e de revalorização nacional que a "Geração dos 900" divulgou. Trazia como propaganda, principalmente, a grandeza da "raça paraguaia” mestiça. No interior do livro, O’Leary aponta que apenas os paraguaios seguem sendo os retardatários mencionados por Sarmiento. Embora diversos poetas estrangeiros tenham feito coro à apoteose histórica do país - como Rubén Darío, Blanco Fomblona, 
etc. -, a América ainda esperava o poeta paraguaio que rimasse a epopeia nacional.

Na capa do livro, como subtítulo, figurava a legenda "Juicio de José Enrique Rodó”, que se tratava de uma carta que o autor havia escrito a O'Leary em 1915, utilizada por este último como prólogo à sua obra. Nesta carta, Rodó mostra estar convencido da intepretação de O'Leary sobre a guerra.

Contribuyen al interés de ese estudio tanto el desempeño del narrador como el tema sobre que versa. He considerado siempre que la guerra entre la Triple Alianza y el Paraguay es uno de los hechos más complejos de la historia americana; y en alguna de sus relaciones, uno de los que imponen mayores torturas de conciencia para completar un juicio cabal y seguro, que, sin olvido de ninguno de los antecedentes y circunstancias con que se vincula aquella gran tragedia, en la vida interna e internacional de los cuatros pueblos que fueron sus actores, permita distribuir con justicia las tremendas responsabilidades que ella envuelve, y fijar, a su respecto, el veredicto histórico. [...]. Así, purificado en el crisol del tiempo, aquel pasado nos une y nos unirá más cada día (Rodó, 1957, p. 1409)21.

Brezzo (2019) aponta que a correspondência desvela a estratégia de O'Leary de solicitar a reconhecidos letrados ou homens públicos que prologassem suas obras sobre a Guerra do Paraguai, como forma de buscarem aliados dentro da região platense e na Europa, visando tanto a consolidação de uma leitura revisionista deste conflito quanto a legitimação de sua própria interpretação intelectual. Rodó morreu em 1917 e a obra de O'Leary foi publicada dois anos depois, portanto, ficou cristalizada a posição rodoniana sobre o texto e a intepretação do intelectual paraguaio sobre a Guerra - a carta, utilizada como uma espécie de prefácio, legitimou a história narrada por O’Leary.

É interessante mencionarmos que, para explicar o que O'Leary denomina "fondo de toda mi propaganda histórica", ele cita um longo trecho de Rodó sobre o sentimento de tradição, oriundo do artigo escrito em 1895 a respeito de Juan Carlos Gómez (1820-1884), importante jornalista e político uruguaio. Ao citar o longo trecho, O’Leary demonstrava uma outra maneira de se pensar o país, que, em decorrência do centenário da independência política, necessitava recuperar o orgulho, a união, o sentimento nacional e de raça paraguaia - ou seja, apontava que era preciso reparar-se a nação e, ao mesmo tempo, torná-la parte da história continental, não como o país vencido na Guerra, mas sim por sua bravura, sua glória e pela exaltação da civilização guarani. 
Por fim, o poeta paraguaio Eloy Fariña Núñez (1885-1929) escreveu o ensaio "El canto de Ariel", publicado originalmente em 1917, na revista argentina Nosotros, texto que posteriormente compôs a obra intitulada El jardin del silencio, de 1925. Núñez é considerado por alguns críticos - a exemplo de Dolores Philips Lopes (2003) e José Alcalá (1911) - como o poeta modernista paraguaio por excelência. Um dos seus temas literários é a exaltação dos valores nacionais humilhados pela derrota do país na guerra da Tríplice Fronteira. Núñez constata sobre Rodó:

El reveló a millares de almas desorientadas la nobleza de su culto, en una prosa que sería perfecta si la mano del hombre, prisionero de su propia impotencia, fuese capaz de realizar algo perfecto. El ensenó a las nuevas generaciones a un continente la parábola del idealismo. El hizo amar la belleza abstracta del concepto unida a la hermosura plástica de la forma. Porque fue ante todo un pensador que vertía sus ideas bellamente. Y estas ideas eran nobles como que las concebían un espíritu culto, proteico, en sumo grado comprensivo (Núñez, 1925, pp. $118-119)^{22}$.

Este idealismo ao qual se refere Núñez seria o reconhecimento das necessidades espirituais e estéticas da "raça latina", como fatores que permitiam uma coesão identitária, o que, para Castro Morales (2016), significou um pioneirismo da crítica ao imperialismo no século XX. Núñez ressalta primordialmente o caráter magistral da obra do autor, que ensina a parábola do idealismo, abrindo-se ao infinito, ao livre pensar, à compreensão. Segundo Núñez, tal obra representa uma reação espiritual frente ao positivismo científico e à civilização material, por isso, o humanismo é o seu produto mais representativo.

Deste modo, os autores que estamos relacionando neste texto tinham como grande questão a ser resolvida a construção de um sistema de pensamento sobre suas realidades. Estamos diante, portanto, de uma tentativa de recuperação de uma história cultural da América Latina, em que o arielismo pode ser lido como um fenômeno estético e político que alcançou circulação no Paraguai. O continentalismo, que expande a noção de nacionalismo, abre espaço à inserção de todos os países nessa "pátria intelectual" rodoniana, cujos mesmos fatores formativos, apoiados na geografia, na história, na "raça", na cultura e nos sentimentos, se reúnem novamente, clamando por uma unidade orgânica, nem que seja a partir da fraternidade intelectual. 


\section{Conclusões}

Como vimos, a fortuna crítica rodoniana aponta com frequência o empenho de José Enrique Rodó em se converter numa espécie de guia intelectual de seu tempo. Para tanto, o pensador uruguaio se utilizou de variadas estratégias no intuito de colocar em circulação suas ideias, principalmente em países da América Latina e na Espanha - dentre elas, as trocas de correspondências, as publicações periódicas e a divulgação de seus textos e livros.

Através dos discursos do livro em homenagem a Rodó, bem como dos comentários de sua obra produzidos desde o início do século XX no Paraguai, observamos a força pedagógica que suas ideias desempenharam neste país, superando as barreiras geográficas e as limitações intelectuais que constantemente se atribuíam à "ilha rodeada de terra". Unida pelo ideal de um renascimento intelectual e físico da pátria, tentando criar elites intelectuais próprias, essa geração acessou os trabalhos de Rodó, que fez vibrar novas esperanças com seu impulso idealista, auxiliando na ideia de pertencimento dessa intelectualidade paraguaia à "pátria intelectual”.

Rodó pensava e se expressava em termos geracionais. Se sua obra pode ser encarada como o vetor na construção de espaços de produção de conhecimento no continente, ele o fez a partir dos sermões laicos, no campo da literatura de ideias. Para García Morales (1992), essa foi uma alternativa ao modernismo que, neste momento, predominava na Hispano-América, o qual o crítico via como insubstancial.

Este discurso permanece para a posteridade, como observa-se, no Paraguai, nas homenagens e nos textos posteriores à sua morte. Os trechos dos autores e do próprio Rodó mencionados revelam que a noção de cultura foi um dos assuntos que tiveram mais adesão dos intelectuais paraguaios. Essa noção enfatizava um caráter espiritual da alta cultura e, ao mesmo tempo, a necessidade de a população iletrada ou pouco letrada acessá-la, pois, até então, ela era restrita à elite intelectual europeia.

Para Ignacio Pane, a importância de Ariel está em escapar das adversidades da difícil transição do século XIX para o XX, de superar a aridez do utilitarismo, além de Rodó ser um jovem intelectual que trouxe "frescor" ao pensamento hispano-americano. A homenagem da juventude paraguaia prestada pelo Centro de Estudantes de Direito aponta um eco de seus ensinamentos no país. Conforme os depoimentos apontados, observamos um ressentimento pela sua morte precoce. Ao mesmo tempo, se suas palavras tinham como alvo 
essa juventude, elas foram compreendidas e incorporadas por esses jovens estudantes. Isso assinala a longevidade e o alcance do projeto arielista.

Quanto a Rafael Barrett, lemos seu apelo para que surgissem mais autores talentosos e mestres como Rodó no restante da América, os quais não se apegariam a dogmas, e sim ao livre pensamento e à cultura. No que diz respeito a O’Leary, observamos a importância que ele atribuía a Rodó, ao incorporar, em suas percepções sobre a Guerra contra o Paraguai, a carta-prólogo de Rodó que respaldava suas interpretações, transfiguradas pelo nacionalismo histórico da reconstrução nacional. Já o poeta Núñez enxerga no canto a Ariel uma beleza e uma perfeição que servem como guias para todos os jovens do continente.

Todos esses ecos de Rodó no Paraguai serviram para o fomento de contatos, projetos e para a constatação das semelhanças existentes na formação histórica colonizada dos países do continente, estabelecendo-se, idealmente, a América Latina como uma só pátria transnacional. Apesar disso, Rodó tinha consciência das diferenças entre as nações, tanto que, em texto de 1916, intitulado "Al concluir el año", escrito quando passava uma temporada na Europa, argumentou que, para o olhar europeu, toda a América espanhola seria uma só entidade, uma só imagem e teria um só valor. Porém, segundo o autor, se por um lado essa generalização conduzia a enormes erros, ela ao mesmo tempo apontava para uma "unidade espiritual" das nações, que estaria acima das fronteiras nacionais.

Pode-se observar que esses intelectuais que vivenciaram o final do século XIX e o início do XX apostaram na existência de uma cultura latino-americana, definida por traços gerais compartilhados pelas nações da região, malgrado as inegáveis assimetrias provocadas pelas questões culturais, econômicas, políticas e étnicas que separavam uma nação da outra. Os autores paraguaios mencionados, leitores e admiradores de Rodó, ao aderirem aos ensinamentos arielistas, condensaram uma revalorização intelectual de seu país e demonstraram que, apesar das dificuldades surgidas após o massacre da Guerra do Paraguai, sua juventude poderia, sim, atuar como agente transmissora do humanismo espiritualizado e integrar a pátria intelectual que Rodó tanto conclamou e convocou na América Latina.

Desta forma, podemos concluir que há a necessidade de se compreender a importância dos ideais de José Enrique Rodó e a centralidade de sua obra no horizonte literário para além do Uruguai. Percebemos que suas ideias ecoaram fortemente no Paraguai e o mesmo ocorreu em outros países hispano-americanos. 


\section{REFERÊNCIAS}

ACOSTA, Yamandú. Ariel: evangelio de una teología profana americanista. Utopía y praxis latinoamericana: revista internacional de filosofía iberoamericana y teoría social, n. 81, pp. 31-44, 2018.

ALCALÁ, H. R. Historia de la literatura paraguaya. Madrid: Ediciones S. M., 1970.

AMARAL, Raúl. El novecentismo paraguayo: hombres e ideas de una generación fundamental del Paraguay. Asunción: Servi Libro, 2006.

ARDAO, Arturo. Rodó: su americanismo. Montevideo: Biblioteca de Marcha, 1970.

BARRETT, Rafael. "Motivos de Proteo" y "El libro de Rodó". In: Al margen. Montevideo: O. M. Bertani, 1912. pp. 25-34.

BREZZO, Liliana Maria. "Reparar la nación”. Discursos históricos y responsabilidades nacionalistas en Paraguay. Historia Mexicana, El Colegio del México, v. LX, n. 237, pp. 98-123, 2010.

BREZZO, Liliana. Cartas prodigiosas. Juan E. O’Leary y los entresijos de la edición de sus relatos históricos sobre la Guerra del Paraguay (1919-1929). Páginas: Revista Digital de la Escuela de Historia, n. 11, n. 25, pp. 1-18, 2019.

BREZZO, Liliana M. El centenario en Paraguay: Historiografía y responsabilidades nacionalistas (1897-1912). Anuario del CEH, n. 4, pp. 57-74, 2004.

CABALLERO CAMPOS, Hérib. Entre Clío y Astrea: La Biblioteca Paraguaya del Centro de Estudiantes de Derecho. Diálogos, v. 21, n. 1, pp. 13-25, 2017.

CESANA, Raffaele Gian Luigi. José Enrique Rodó en México. Tesis (Doctorado en Letras) - Facultad de Filosofía y Letras. Universidad Nacional Autónoma de México. México, 2016.

CORRAL SÁNCHEZ-CABEZUDO, Francisco. El pensamiento de Rafael Barrett, un “joven del 98” en el Río de la Plata. Revista de Hispanismo Filosófico, n. 3, pp. 17-32, 1998.

COSTA, René de. Una carta inédita de José Enrique Rodó: Rodó y la literatura chilena. Revista Iberoamericana, v. XXXVI, n. 73, pp. 651-655, 1970.

DEVÉS-VALDÉS, Eduardo. Redes intelectuales en América Latina: hacia la constitución de una comunidad intelectual. Santiago de Chile: Universidad de Santiago de Chile, 2007.

DEVÉS-VALDÉS, Eduardo. Pensar (en) Paraguay hacia el 2000. Los desafíos de la intelectualidad paraguaya. In: BOSIO, B, G; DEVÉS-VALDÉS, Eduardo. Pensamiento paraguayo del siglo XX. Asunción: Intercontinental Editora, 2006. pp. 299-332.

DEVÉS-VALDÉS, Eduardo. Pensamiento Periférico; Asia - África - América Latina -Eurasia y algo más. Una tesis interpretativa global. Buenos Aires: Clacso/IDEA-USACH, 2012. 
ETCHEVERRY, José Enrique. Rodó y el Brasil. Montevideo: Publicaciones del Instituto de Cultura Uruguayo-Brasileño, 1950a.

ETCHEVERRY, José Enrique. La Revista Nacional (1895-1897), Montevideo, ns. 6/8, pp. 263-286, jun. 1950b.

GARCÍA MORALES, Alfonso. Literatura y pensamiento hispánico de fin de siglo: Clarín y Rodó. Sevilla: Universidad de Sevilla, 1992.

GONZÁLEZ, Natalício. Rodó. Asunción: Biblioteca Paraguaya del Centro de Estudiantes de Derecho; Imprenta Ariel, 1919.

MAÍZ, Claudio. Constelaciones Unamunianas. Enlaces entre España y América (18981920). Salamanca: Ediciones Universidad de Salamanca, 2009.

MAKARAN, Gaya. Paraguay: ¿Isla rodeada de tierra? Una historia de la (NO) integración nuestroamericana. Revista Estudios Paraguayos, v. XXXIV, n. 2, pp. 7-40, 2016.

MAKARAN, Gaya. La imagen de la mujer en el discurso nacionalista paraguayo. Latinoamérica: Revista de estudios Latinoamericanos, México, n. 57, pp. 43-75, 2013.

MONEGAL, Emir Rodríguez. Las relaciones de Rodó y Francisco García Calderón. Número, Montevideo, año 5, ns. 23-24, pp. 255-262, 1953.

MONEGAL, Emir Rodrigues. Prologo. In: RODÓ, José Enrique. Obras Completas. Edición, introducción, prólogo y notas de Emir Rodríguez Monegal. Madrid: Aguilar, 1957. pp. 13-136.

MORALES, Belén Castro. José Enrique Rodó en su tiempo y en sus obras. Madrid: Biblioteca Virtual Ignacio Larramendi de Polígrafos, 2016.

MORALES, Belén Castro. Maestros y discípulos, de Monterroso a Rodó. Anales de Literatura Hispanoamericana, n. 28, pp. 507-518, 1999.

MORALES, Belén Castro. Introducción. In: RODÓ, José Enrique. Ariel. Madrid: Cátedra, 2004. pp. 9-135.

MORINIGO, Mariano. Americanismo literario: formas antagónicas. Tucumán: Facultad de Filosofía y Letras, Universidad de Tucumán, 1967.

NÚÑEZ, Eloy Fariña. El jardín del silencio: ensayos filosóficos. Asunción: H. Kraus, 1925.

O’LEARY, Juan. Nuestra Epopeya: guerra del Paraguay. Asunción: La Mundial, 1919.

PANE, Ignácio A. “Ariel” por Enrique Rodó. Revista del Instituto Paraguayo, Asunción, n. 3, pp. 197-210, 1901.

REAL DE AZÚA, Carlos. Prólogo a Ariel. In: RODÓ, José Enrique. Ariel. Motivos de Proteo. Caracas: Biblioteca Ayacucho, 1976. pp. IX-XCV.

RAMOS, Julio. Desencontros da modernidade na América Latina: literatura e política no século 19. Tradução de Rômulo Monte Alto. Belo Horizonte: Editora UFMG, 2008.

ROA BASTOS, Augusto. Paraguay. Isla rodeada de tierra. El correo de la París: Unesco, 1977. Disponível em: http://www.lacult.unesco.org/docc/oralidad_06_07_56-59-paraguay.pdf. Acesso em: 10 nov. de 2020. 
RODÓ, José E. Mensaje al Paraguay. In: STEFANICH, Juan (Coord.). Rodó. Asunción: Biblioteca Paraguaya del Centro de Estudiantes de Derecho; Imprenta Ariel, 1919. pp. 43-45.

RODÓ, José E. Palabras a la juventud. In: STEFANICH, Juan (Coord.). Rodó. Asunción: Biblioteca Paraguaya del Centro de Estudiantes de Derecho; Imprenta Ariel, 1919. pp. 41-42.

RODÓ, José Enrique. Obras completas. Edición, introducción, prólogo y notas: Emir Rodríguez Monegal. Madrid: Aguilar, 1957.

SAGUIER, R. Bareiro Rúben. El criterio generacional en la literatura paraguaya. Revista Iberoamericana, v. XXX, n. 58, pp. 293-303, 1964.

SAN ROMÁN, Gustavo. La recepción de Rodó en Cuba. Revista de la Biblioteca Nacional, Montevideo, v. 1, n. 3, pp. 71-86, 2009.

STEFANICH, Juan. Rodó: homenaje de la juventud paraguaya. Asunción: Biblioteca Paraguaya del Centro de Estudiantes de Derecho; Imprenta Ariel, 1919.

STEFANICH, Juan. Prólogo. In: FARIÑA NÚÑEZ, Eloy. El jardín del silencio: ensayos filosóficos. Asunción: H. Kraus, 1925.

WEINBERG, Liliana. José Enrique Rodó: las distintas modulaciones de la voz del maestro. Latinoamérica, México, n. 66, pp. 45-67, 2018.

ZEA, Leopoldo. Ariel, un siglo después, In: ZEA, Leopoldo; TABOADA, Hernán Taboada (Orgs.). Arielismo y globalización. México: Instituto Panamericano de Geografía e Historia; Fondo de Cultura Económica, 2002. pp. 5-12.

\section{NOTAS}

${ }^{1}$ No original: 'O fato fundamental de que somos essencialmente 'um'; de que o somos apesar das diferenças, mais exageradas que profundas, facilmente perceptíveis de perto, e de que o seremos ainda mais no futuro, até que nossa unidade espiritual ultrapasse as fronteiras nacionais e prevaleça na realidade política".

${ }^{2}$ No original: "Eu creio que a América precisa enormemente de sua juventude".

${ }^{3}$ No original: "Para o autor de Ariel, sempre foi uma ideia cativante a publicação de uma revista americana, que significava a ágora intelectual das novas gerações e o instrumento mais adequado para conquistar a confraternidade do Continente".

${ }^{4}$ No original: "Parecerá punível aos que defendem como o sagrado símbolo da nacionalidade intelectual o isolamento receoso e estreito, a ferocidade da independência literária, que só dá de si uma originalidade obtida a preço da incomunicação e da ignorância ingênua".

${ }^{5}$ No original: "Desta forma, o esforço paraguaio de integração cultural com o continente inicia-se com a negação persecutória de si próprio, construída ao longo da sua história marcada pelo isolamento."

${ }^{6}$ No original: “À sua venerável sombra o coração dos orientais pede hoje bênçãos para a 
terra paraguaia; bênçãos que frutifiquem em paz e ventura para seu povo; em progresso triunfante para sua civilização, tão esforçadamente mantida em promessas por sua generosa juventude”.

${ }^{7}$ No original: "Afirmar os valores espirituais da nação renascida da catástrofe".

${ }^{8}$ No original: "Na hora de se pensar horizontalmente Sul-Sul, as redes intelectuais permitem descobrir circulações com maior eficácia do que a noção de 'influência', carregada tantas vezes pela verticalidade Norte-Sul”.

${ }^{9}$ No original: "Paraguaios e orientais formam, sem dúvida, o mais cabal exemplo americano daquela 'grande amizade' que Michelet sonhava ver consagrada nas relações entre os povos. Reciprocidade de afetos e comunidade de interesses os vinculam. O Uruguai é o Paraguai Atlântico, o Paraguai é o Uruguai dos trópicos”.

${ }^{10}$ No original: "E, no entanto, aqui em Assunção eu juraria que não são mais de quatro os que sequer ouviram este nome Ariel, simplesmente porque não chegou um número maior de exemplares do livro".

${ }^{11}$ No original: "Já que todos trabalhamos no estúdio, nem todos na oficina, nem todos na escrivaninha, que todos nós possamos ir pelo menos ao Ateneu. Eu estou com ele. Creio, como ele, que a especialização do progresso produz a estreiteza do horizonte individual, se a correção da arte ou da religião não forem aplicadas. Mas não vou mais além, não vou ao ponto de pensar, como Próspero, que esta estreiteza individual mata o sentimento de solidariedade. Pelo contrário, parece-me criá-lo; pois quanto menos cada um é capaz de se sustentar, mais necessita dos outros. E é na necessidade, no interesse que reside a base da solidariedade. Só a caridade, entre laços individuais-sociais, se funda no afeto puro".

${ }^{12}$ No original: "No Paraguai, entretanto, a menos que eu esteja exagerando, não posso negar que a primeira coisa a se fazer é começar. Que se deve subir, não descer; isto é, entrar no andar térreo, e depois ir ao mirante; mas, claro, assegurando-se de antemão um elevador ou uma escada: tendo como catecismo um livro como Ariel".

${ }^{13}$ No original: "Porque, sim, a comunidade de origem, de idioma, de tradição, de costumes, de instituições, de interesses, de destinos históricos; e de contiguidade geográfica, e tudo o que pode dar fundamento real à ideia de uma pátria, não são suficientes para que a língua do coração apague, entre nossos povos, as convencionais fronteiras e dê nome de 'pátria'”.

${ }^{14}$ Em 1920, a Revista Ariel, órgão do Centro de Estudantes de Direito de Montevidéu, também publicou um número dedicado a José Enrique Rodó, no qual foram impressos textos escritos logo após sua morte e também na década de 1920. Os organizadores encaram o número como uma oferenda a Rodó, o Mestre da América. Ambas as publicações reforçam a percepção do prestígio do autor entre a juventude do continente.

${ }^{15}$ No original: "Eleve a nobre, a viril juventude paraguaia, seu generoso espírito à altura dessa necessidade dos tempos; faça obra de paz com a palavra e com a ação; valorize sua altivez heroica em vencer dentro de si mesma a tentação das paixões, e há de ganhar uma glória tão alta e tão pura que nenhuma geração poderá aspirar a outra maior”.

${ }^{16}$ De acordo com Francisco Corral Sánchez-Cabezudo (1998), Barrett integrava a geração de 1898 espanhola, que chegou à América do Sul no início do século XX. O autor não se 
identifica com o grupo paraguaio da "Geração dos 900" no que concerne à interpretação sobre a Guerra, que, na sua visão, servia para fabricar mitos, erigir heróis, em suma, para construir um sentimento de coletividade nacional.

${ }^{17}$ No original: "Que necessitados estão o Paraguai, e a América inteira, de talentos como Rodó, de mestres como ele, se é certo chamar mestre aos que evitam toda a liderança, aos campeões da tolerância que nos empurram para um só caminho, mas iluminam a todos; aos que não nos propõem uma teoria única, nem um dogma, pois eles nos dizem: Sejam livres! Aos que nos ordenam uma obra particular, mas nos desatam as mãos!"

${ }^{18}$ A análise é descrita por Rodó como parte de "uma carta íntima” (Rodó, 1957, p. 635).

${ }^{19}$ No original: "Uma das impressões a partir das quais eu poderia concretizar os ecos de simpatia que a leitura de suas crônicas desperta no meu espírito a cada momento é a de que, no nosso tempo, mesmo aqueles de nós que não são socialistas, nem anarquistas, nem nada do gênero, na esfera da ação ou da doutrina, trazem dentro de nossas almas uma profundidade mais ou menos consciente de protesto, de descontentamento, de desajustamento contra tanta injustiça brutal, contra tantas mentiras hipócritas, contra tanta vulgaridade entronizada e odiosa, como tem entretecido, em sua urdidura, esta ordem social transmitida no século que começa pelo advento da burguesia e da democracia utilitária".

${ }^{20}$ No original: "O que sinto - agrego para terminar - diante do êxito definitivo de minha propaganda, é, sobretudo, um imenso otimismo, que me faz crer que dias melhores esperam o Paraguai, dias de reconciliação e paz, dias de prosperidade, nos quais seguramente voltaremos a ser o que fomos, fortes e respeitados, algo mais do que uma simples expressão geográfica, um fator decisivo nos destinos da América”.

${ }^{21}$ No original: "Contribuem para o interesse deste estudo tanto o desempenho do narrador como o tema sobre o qual versa. Sempre considerei que a guerra entre a Tríplice Aliança e o Paraguai é um dos acontecimentos mais complexos da história americana; e em algumas das suas relações, um dos que impõem maiores torturas de consciência para se completar um julgamento cabal e seguro, que, sem nos esquecermos de nenhum dos antecedentes e das circunstâncias com que essa grande tragédia está ligada, na vida interna e internacional dos quatro povos que foram seus atores, permita-nos distribuir com justiça as tremendas responsabilidades que ela envolve, e fixar, a seu respeito, o veredicto histórico. [...]. Assim, purificado no crisol do tempo, esse passado nos une e nos unirá cada vez mais a cada dia".

${ }^{22}$ No original: "Ele revelou a milhares de almas desorientadas a nobreza de seu culto, em uma prosa que seria perfeita se a mão do homem, prisioneiro de sua própria impotência, fosse capaz de realizar algo perfeito. Ele ensinou às novas gerações de um continente a palavra do idealismo. Ele fez com que se amasse a beleza abstrata do conceito unida à formosura plástica da forma. Porque foi, antes de tudo, um pensador que vestia suas ideias com beleza. E estas ideias eram nobres como as que concebiam um espírito culto, proteico, em sumo grau compreensivo".

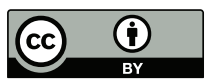

Artigo submetido em 21 de janeiro de 2021.

Aprovado em 13 de agosto de 2021. 